\title{
TURISMO DE BASE COMUNITÁRIA: UMA REVISÃO SISTEMÁTICA E BIBLIOMÉTRICA DA LITERATURA
}

\author{
Bruna Ranção Conti \\ Doutorado em Políticas Públicas, Estratégias e Desenvolvimento - PPED/UFRJ \\ Universidade Federal do Estado do Rio de Janeiro \\ bruna.conti@unirio.br \\ José Tavares Spinola \\ Graduação em Turismo (em curso) - UNIRIO \\ Universidade Federal do Estado do Rio de Janeiro \\ tavares.ze@edu.unirio.br \\ Luiz Saldanha \\ Mestrado em Engenharia de Transportes - Coppe/UFRJ \\ Universidade Federal do Rio de Janeiro \\ luizsaldanha@pet.coppe.ufrj.br
}

\section{Resumo}

Objetivo: Apresentar o estado da arte das pesquisas científicas em turismo de base comunitária (TBC). Metodologia: Revisão Sistemática da Literatura e estudo bibliométrico sobre a produção científica em TBC. Utilizou-se base de periódicos mundiais e a busca por artigos em língua inglesa, espanhola e portuguesa, evidenciando aspectos como: evolução das publicações na área, artigos mais citados, principais periódicos e autores, palavras-chave mais utilizadas, além de análise dos principais temas abordados nos artigos, metodologias aplicadas e mapeamento dos estudos de caso realizados. Os artigos foram analisados utilizando-se os softwares Microsoft Excel, Iramuteq e Gephi.

Originalidade/relevância: $\mathrm{O}$ artigo apresenta a discussão científica sobre TBC. Apesar de já existirem estudos nesse sentido, estes contemplam recortes mais limitados e um número menor de artigos analisados. Além disso, são utilizados softwares que possibilitam melhor organização e visualização das informações.

Principais resultados: Verifica-se que as pesquisas em TBC se iniciam na década de 1980, mas ganham volume na última década. Os temas mais recorrentes são a participação comunitária e a sustentabilidade ambiental associada ao TBC. Os artigos se utilizam, em sua maioria, de técnicas qualitativas de pesquisa, incluindo diversos estudos de caso, sendo os continentes Asiático, Americano e Africano os mais estudados, respectivamente.

Contribuições teóricas/metodológicas: São evidenciados o estágio atual e a amplitude da discussão acadêmica internacional sobre o tema. As correlações entre as diferentes abordagens metodológicas podem contribuir para a internacionalização de debates locais e orientar análises comparativas de políticas públicas de TBC entre países.

Palavras-chave: Turismo de base comunitária. Produção científica. Revisão sistemática. Bibliometria.

\section{$\underline{\text { Cite como }}$}

American Psychological Association (APA)

Conti, B. R., Spinola, J. T., \& Saldanha, L. (2021, set./dez.). Turismo de base comunitária: uma revisão sistemática e bibliométrica da literatura. PODIUM Sport, Leisure and Tourism Review, São Paulo, 10(4), 50-80. https://doi.org/10.5585/podium.v10i4.18955. 


\title{
COMMUNITY-BASED TOURISM: A SYSTEMATIC AND BIBLIOMETRIC REVIEW OF THE LITERATURE
}

\begin{abstract}
Objective: To present the state of the art of scientific research on Community-based Tourism (CBT). Methodology: Systematic Literature Review and bibliometric study on scientific production in CBT. A base of world journals and search for articles in English, Spanish, and Portuguese were used, showing aspects such as the evolution of publications in the area, the most cited articles, main journals and authors, the most used keywords, along with analysis of the main themes covered in the articles, the applied methodologies and the mapping of the case studies performed. The articles were analyzed using Microsoft Excel, Iramuteq, and Gephi software.

Originality / relevance: The article presents the scientific discussion on CBT. Although there are already studies in this direction, they include more limited cuts and a smaller number of articles analyzed. In addition, the use of software allowed a better organization and visualization of the information.

Main results: It appears that research on CBT started in the 1980s, but gained volume in the last decade. The most recurring themes are community participation and environmental sustainability associated with CBT. Most articles use qualitative research techniques, including several case studies, with the Asian, American, and African continents being the most studied, respectively.

Theoretical / methodological contributions: The current stage and the scope of the international academic discussion on the topic are highlighted. The correlations between the different methodological approaches can contribute to the internationalization of local debates and guide comparative analysis of public policies on CBT between countries.
\end{abstract}

Keywords: Community-based Tourism. Scientific production. Systematic review. Bibliometry.

\section{TURISMO DE BASE COMUNITARIA: UNA REVISIÓN SISTEMÁTICA Y BIBLIOMÉTRICA DE LA LITERATURA}

\section{Resumen}

Objetivo: Presentar el estado del arte de la investigación científica en Turismo de Base Comunitaria (TBC).

Método: Revisión sistemática de la literatura y estudio bibliométrico sobre la producción científica en TBC. Se utilizó una base de revistas científicas globales y la búsqueda de artículos en inglés, español y portugués, resaltando aspectos como: evolución de las publicaciones del área, artículos más citados, principales revistas y autores, palabras clave más utilizadas, además del análisis de los principales temas tratados en los artículos, metodologías aplicadas y mapeo de los estudios de caso realizados. Se analizaron los artículos con los softwares Microsoft Excel, Iramuteq y Gephi.

Originalidad/Relevancia: Este artículo presenta la discusión científica sobre TBC. Aunque existan estudios en esta dirección, estos incluyen cortes más limitados y menor número de artículos analizados. Además, se utilizó softwares que permitan mejor organización y visualización de la información.

Principales resultados: Se identificó que la investigación sobre la TBC comenzó en la década de 1980, pero ha aumentado significativamente en la última década. Los temas más recurrentes son la participación comunitaria y la sostenibilidad ambiental asociados al TBC. La mayoría de los artículos utilizan técnicas de investigación cualitativa, incluyendo estudios de casos, en que los continentes asiático, americano y africano son los más estudiados, respectivamente.

Contribuciones teóricas/metodológicas: Este artículo destaca la etapa actual de la discusión académica internacional sobre el tema y señala nuevas posibilidades de investigación, como estudios dirigidos al análisis comparativo de políticas públicas en TBC entre países.

Palabras clave: Turismo comunitario. Producción científica. Revisión sistemática. Bibliometría. 
Conti, B. R., Spinola, J. T., \& Saldanha, L. (2021, set./dez.). Turismo de base comunitária: uma revisão sistemática e bibliométrica da literatura

\section{Introdução}

Este trabalho compõe o conjunto de pesquisas desenvolvidas em torno da temática do turismo de base comunitária (TBC), visando aprofundar a discussão científica sobre o tema. Para isso, como etapa fundamental, encontra-se a necessidade de entendimento do estado da arte das pesquisas nacionais e internacionais em TBC, ou turismo comunitário ${ }^{1}$. Este estudo busca, portanto, mapear a evolução da discussão científica existente sobre TBC, apontar as principais discussões teóricas sobre o assunto e levantar as ferramentas metodológicas utilizadas pelos principais autores da área (Chueke \& Amatucci, 2015). Apesar de já existirem estudos nesse sentido (Graciano \& Holanda, 2020; Grimm et al., 2017; Vieira \& Gomes, 2020), o presente artigo contempla um recorte de investigação mais abrangente, analisando um número maior de artigos.

Em linhas gerais, o TBC vem sendo entendido como um fenômeno social que busca ir além dos resultados econômicos do turismo e incorporar a valorização dos saberes tradicionais e da cultura local, o fortalecimento das relações sociais, a melhoria da qualidade de vida dos agentes envolvidos no processo e a conservação dos recursos naturais. Constitui-se, também, como uma forma de organização do turismo que propõe o protagonismo da população local na gestão dessa atividade econômica, por meio de mecanismos de autogestão, da manutenção da propriedade do território e da democratização de oportunidades e benefícios (Conti \& Antunes, 2020).

Assim, para o TBC, o turismo deixa de ser mera atividade econômica nos moldes de um capitalismo selvagem, para incorporar os princípios da cooperação na gestão dos empreendimentos da própria localidade, as territorialidades locais como elementos fundamentais para a criação de valor turístico e o protagonismo da população local na busca por um desenvolvimento endógeno (Conti et al., 2018).

A partir desses apontamentos iniciais, o objetivo deste trabalho é realizar uma revisão sistemática da literatura e apresentar o estado da arte das pesquisas científicas em TBC, nos contextos nacional e internacional.

A proposta de revisão sistemática da literatura inclui ainda um estudo bibliométrico sobre a produção científica em TBC, evidenciando aspectos como a evolução temporal das publicações sobre o tema, os artigos com maior número de citações, os principais periódicos e

\footnotetext{
${ }^{1}$ Expressões utilizadas como sinônimas pela maioria dos pesquisadores, o que também será considerado para a realização deste trabalho. A mesma
} recomendação encontra-se no Tesauro Brasileiro de Turismo. Disponível em: http://www2.eca.usp.br/tesauroturismo/. Acesso em: 17 mar 2020. 
autores, as palavras-chave recorrentes, além de uma análise qualitativa sobre os principais temas abordados nos artigos, as metodologias aplicadas e os estudos de caso já realizados.

Este artigo está estruturado em cinco seções. Na seção a seguir está detalhado o caminho metodológico seguido nesta pesquisa. Na sequência, a fundamentação teórica é apresentada, tendo como base os principais artigos sobre TBC já publicados. Na quarta seção é apresentado o levantamento bibliométrico realizado, assim como as análises e discussões dos resultados encontrados. Por fim, são apresentadas as considerações finais do trabalho.

\section{Caminho metodológico da pesquisa}

Nesta seção é descrito o processo seguido para a preparação, análise e apresentação da revisão sistemática da literatura sobre $\mathrm{TBC}$, associada ainda à revisão bibliométrica como método de mapeamento e sistematização da produção científica.

Inicialmente, é preciso destacar que a revisão da literatura compreende o levantamento da produção científica disponível, a partir da compilação e entendimento dos conceitos anteriores à investigação que já foram objeto de tratamento analítico em estudos precedentes (Laville \& Dionne, 1999). Assim, a revisão da literatura visa compreender as bases científicas e teóricas que compõem a construção de dado conhecimento (Panosso-Netto \& Nechar, 2014).

As revisões sistemáticas da literatura são utilizadas com o objetivo de identificar eventuais lacunas de investigação na pesquisa existente (Busalim \& Hussim, 2016), consistindo em um método de identificação, avaliação e interpretação de um objeto específico (Sonego \& Echeveste, 2016). Uma das principais características deste tipo de revisão é a abrangência na coleta de dados e a divulgação dos critérios de pesquisa adotados, a fim de permitir sua replicação (Galvão \& Pereira, 2014).

A revisão sistemática da literatura é composta por fases, esquematizadas na tabela a seguir: 
Conti, B. R., Spinola, J. T., \& Saldanha, L. (2021, set./dez.). Turismo de base comunitária: uma revisão sistemática e bibliométrica da literatura

\section{Tabela 1}

Fases da Revisão Sistemática da Literatura

\begin{tabular}{|c|l|l|}
\hline 1 & $\begin{array}{l}\text { Elaboração da pergunta } \\
\text { norteadora }\end{array}$ & $\begin{array}{l}\text { Fase em que se determina quais serão os estudos incluídos na } \\
\text { pesquisa, os meios adotados para a identificação desses estudos e as } \\
\text { informações que serão coletadas de cada um. }\end{array}$ \\
\hline 2 & $\begin{array}{l}\text { Busca ou amostragem na } \\
\text { literatura }\end{array}$ & $\begin{array}{l}\text { Nesta fase a busca na base de dados deve ser ampla e diversificada. } \\
\text { Os critérios de amostragem precisam garantir a representatividade } \\
\text { da amostra, sendo importantes indicadores da confiabilidade e da } \\
\text { fidedignidade dos resultados. O ideal é incluir todos os estudos } \\
\text { encontrados ou a sua seleção randomizada; ou ainda, é possível } \\
\text { trabalhar com a definição de critérios claros de inclusão e exclusão } \\
\text { de artigos. }\end{array}$ \\
\hline 3 & Coleta de dados & $\begin{array}{l}\text { Fase em que os dados são extraídos dos artigos selecionados. Estes } \\
\text { dados devem incluir o tamanho da amostra, metodologias utilizadas, } \\
\text { conceitos basilares, mensuração de variáveis, dentre outros. }\end{array}$ \\
\hline 4 & Análise crítica & $\begin{array}{l}\text { Fase em que os estudos selecionados são analisados de forma crítica, } \\
\text { levando-se em consideração a experiência do pesquisador. }\end{array}$ \\
\hline 5 & $\begin{array}{l}\text { Discussão dos resultados e } \\
\text { apresentação final }\end{array}$ & $\begin{array}{l}\text { Nesta fase os resultados são apresentados a partir de sínteses, } \\
\text { interpretações e eventual comparação entre os dados evidenciados } \\
\text { na análise dos artigos. }\end{array}$ \\
\hline
\end{tabular}

Fonte: Elaboração própria a partir de Souza et al. (2010) e Ganong (1987).

A revisão sistemática oferece, portanto, um resumo da literatura existente somado à interpretação crítica do diagnóstico realizado, podendo resultar em avanços teóricos relacionados ao fenômeno em questão, principalmente por evidenciar lacunas e novas possibilidades de investigação.

A revisão bibliométrica, como parte da revisão sistemática da literatura, permitirá a identificação do panorama buscado (Albach, 2015), e a análise deste panorama a partir de aspectos qualitativos e quantitativos, o que será executado neste trabalho. A bibliometria é, portanto, um meio utilizado para organização e análise de informações acadêmicas, facilitando a descrição e avaliação da literatura. Além disso, a análise bibliométrica visa fornecer informações úteis para acadêmicos e profissionais no estudo de uma área de pesquisa, fornecendo uma série de indicadores significativos do material bibliográfico, como número de publicações, principais autores (Lei de Lotka), países em que o campo é mais popular, periódicos que lhe dedicam maior atenção (Lei de Bradford), número de citações dos artigos, frequências de palavras-chave (Lei de Zipf), dentre outros (Chueke \& Amatucci, 2015).

Em primeiro lugar, vale destacar que qualquer análise bibliométrica está limitada à disponibilidade, relevância e confiabilidade das informações. Assim, o primeiro passo é identificar o banco de dados a ser utilizado no estudo. Para a busca da produção científica sobre TBC foi selecionada a base Scopus, que reúne periódicos renomados em diversos idiomas, 
inclusão de pesquisadores da área do Turismo e uma variedade de filtros de busca que facilitaram a identificação dos estudos sobre TBC nas línguas pretendidas.

Os critérios de amostragem incluíram, inicialmente, a definição dos termos de busca, o que levou em conta a experiência em pesquisas anteriores realizadas pelos autores deste trabalho e buscas primárias na base escolhida. Foram também realizados pré-testes, adotando termos relacionados com o tema de pesquisa, a fim de se obter como resultado artigos que respondessem ao objetivo do trabalho. Assim, ao final desses testes, foram definidos os termos de busca "turismo de base comunitária" e "turismo comunitário", além de suas variações idiomáticas para o inglês (“community-based tourism" e "community tourism") e para o espanhol ("turismo de base comunitária" e "turismo comunitario").

A busca foi realizada em setembro de 2019, contemplando todos os anos de produção até aquele momento. Na base Scopus foram utilizados os parâmetros de busca "article title", “abstract”, "keywords", “1960 - 2019”, “article”. As buscas foram realizadas nos idiomas "inglês", "português" e "espanhol", todos os arquivos foram exportados em formato CSV considerando as informações relativas a autor, título, fonte e resumo e, posteriormente, organizados e analisados nos softwares Microsoft Excel (versão 2016), Iramuteq (versão 0.7 Alpha 2) e Gephi (versão 0.9.2).

Com o auxílio do Excel foi possível construir a linha do tempo das publicações sobre TBC, identificar os principais autores e suas instituições de filiação, os artigos mais citados, os periódicos mais relevantes para a temática em questão, além dos estudos de caso apresentados nos artigos. Foi ainda neste software que os artigos foram classificados em categorias, o que possibilitou uma análise qualitativa sobre as principais questões que vêm sendo abordadas pelos pesquisadores da área, assim como os aportes teóricos e metodológicos mais utilizados.

Já com o Iramuteq, software que permite análises estatísticas sobre corpus textuais (Camargo, 2005), foi possível construir uma nuvem de palavras (considerando a frequência de todas as palavras-chave utilizadas pelos autores) e uma análise de similitude das palavras que compõem os resumos dos artigos analisados, ou seja, uma análise textual relacional que possibilita identificar as coocorrências entre as palavras e a conexidade entre elas. Por fim, o Gephi permitiu a simplificação gráfica do resultado obtido na análise de similitude, facilitando a observação das interações textuais e garantindo uma menor poluição visual na apresentação destas. 
Conti, B. R., Spinola, J. T., \& Saldanha, L. (2021, set./dez.). Turismo de base comunitária: uma revisão sistemática e bibliométrica da literatura

A busca inicial, a partir dos critérios anteriormente apresentados, resultou em um total de 505 artigos, mas, excluídas as duplicatas, restaram 481 (95,2\%) publicações. A seguir estão apresentados os resultados da busca:

\section{Tabela 2}

Resultados da Busca na Base Scopus

\begin{tabular}{|c|c|c|}
\hline Idioma & Termo de busca & Quantidade de artigos \\
\hline \multirow{2}{*}{ Português } & "turismo de base comunitária" & 0 \\
\hline & “turismo comunitário" & 1 \\
\hline \multirow{2}{*}{ Espanhol } & "turismo de base comunitaria" & 0 \\
\hline & "turismo comunitario" & 14 \\
\hline \multirow{2}{*}{ Inglês } & “community-based tourism" & 307 \\
\hline & "community tourism" & 183 \\
\hline & SUBTOTAL & 505 \\
\hline & DUPLICADOS & 24 \\
\hline & TOTAL & 481 \\
\hline
\end{tabular}

Fonte: Elaboração própria (2019).

Após leitura e avaliação de todos os títulos e resumos, a fim de verificar se os artigos tratavam de fato do tema TBC, foram excluídos da amostra os artigos que não apresentavam uma discussão teórica ou uma proposta de avaliação, aplicação ou planejamento do TBC. Estes artigos ( $\mathrm{n}=151)$, em sua maioria, apresentam o termo de busca apenas em suas palavras-chave, sendo que este termo não é resgatado no título ou resumo do artigo. Outros indicam, ao final do resumo, o TBC como uma potencialidade para um determinado local, contudo, sem desenvolver qualquer análise ou proposição nesse sentido. Portanto, após exclusão dessas publicações, a amostra final totaliza 330 artigos científicos, analisados na quarta seção deste trabalho.

A seguir está apresentado o referencial teórico, levando em consideração as discussões apresentadas nos artigos de maior relevância acadêmica identificados na base Scopus.

\section{Referencial teórico}

Para a construção deste referencial teórico sobre TBC levou-se em consideração as discussões presentes nos artigos mais citados (mínimo de 100 citações) dentre os 330 levantados para compor a amostra deste trabalho. Foram, portanto, lidos na íntegra o total de 12 artigos, além de terem sido incluídas referências (livros e demais artigos) de domínio prévio dos autores e que estes consideram como basilares ou complementares à discussão teórica e conceitual sobre $\mathrm{TBC}$, destacando-se publicações em revistas brasileiras que não foram 
Conti, B. R., Spinola, J. T., \& Saldanha, L. (2021, set./dez.). Turismo de base comunitária: uma revisão sistemática e bibliométrica da literatura

identificadas na base Scopus, mas que possuem grande relevância a nível nacional e podem contribuir com o debate.

Ressalta-se que o TBC não se reduz a uma modalidade ou segmento de turismo, na verdade, configura-se como uma metodologia de trabalho norteada por premissas que, a médio e longo prazos, visam trazer um aumento na qualidade de vida dos atores diretamente envolvidos (Mielke \& Piegas, 2013). Com isso, o turismo comunitário ultrapassa as relações mercantis, promovendo a interconectividade de modos de vida distintos, buscando estabelecer relações sociais entre visitantes e visitados de diferentes culturas (Sampaio et al., 2014). Assim, o TBC “[...] só poderá ser desenvolvido se os protagonistas deste destino forem sujeitos e não objetos do processo" (Irving, 2009, p. 111).

Bursztyn, Bartholo e Delamaro (2009, p.86) apontam que:

O turismo alternativo de base comunitária busca se contrapor ao turismo massificado, requerendo menor densidade de infraestrutura e serviços e buscando valorizar uma vinculação situada nos ambientes naturais e na cultura de cada lugar. Não se trata, apenas, de percorrer rotas exóticas, diferenciadas daquelas do turismo de massa. Trata-se de um outro modo de visita e hospitalidade, diferenciado em relação ao turismo massificado, ainda que porventura se dirija a um mesmo destino. Esse turismo respeita as heranças culturais e tradições locais, podendo servir de veículo para revigorá-las e mesmo resgatá-las. Tem centralidade em sua estruturação o estabelecimento de uma relação dialogal e interativa entre visitantes e visitados. Nesse modo relacional, nem os anfitriões são submissos aos turistas, nem os turistas fazem dos hospedeiros meros objetos de instrumentalização consumista. (Bursztyn, I.; Bartholo, R.; Delamaro, M., 2009, p. 86).

Fabrino, Nascimento e Costa (2016), ao analisarem a literatura nacional existente sobre o TBC, identificaram seis aspectos teóricos, que convencionaram chamar de elementos-chaves, considerados, segundo a análise dos autores, como fundamentais na constituição do turismo comunitário, a saber: (i) Dominialidade, (ii) Organização Comunitária, (iii) Democratização de Oportunidades e Repartição de Benefícios, (iv) Integração Econômica; (v) Interculturalidade; e (vi) Saneamento Ambiental.

A Dominialidade compreende as questões do protagonismo das comunidades no desenvolvimento do turismo. Já a partir do entendimento da Organização Comunitária analisam-se as formas de organização pertencentes à comunidade e, também, as articulações externas que fornecem apoio para o desenvolvimento do turismo. Os elementos Democratização de Oportunidades e Repartição de Benefícios está voltado à investigação das formas como os comunitários se organizam para divisão dos benefícios do turismo. Com a análise da Integração Econômica busca-se identificar o grau de inserção da população local na base da cadeia produtiva do turismo, produzindo insumos e fornecendo-os para a própria comunidade, que, por sua vez, vai gerar produtos para serem comercializados aos turistas. No 
Conti, B. R., Spinola, J. T., \& Saldanha, L. (2021, set./dez.). Turismo de base comunitária: uma revisão sistemática e bibliométrica da literatura

elemento Interculturalidade observa-se o espaço como um lugar de convivência e trocas culturais entre visitantes e visitados. E a Qualidade Ambiental é o elemento que identifica as formas de gerenciamento de resíduos sólidos, efluentes e tratamento de água da comunidade, além da maneira como os recursos naturais são manejados sob as perspectivas institucional e técnica (Fabrino, Nascimento \& Costa, 2016).

Com relação aos artigos internacionais de maior relevância, é possível identificar que questões como colaboração, protagonismo das comunidades e relações de poder são discussões prementes para os pesquisadores do TBC (Keogh, 1990; Jamal \& Getz, 1995; Reed, 1997; Mitchell \& Reid, 2001; Wearing \& McDonald, 2002; Blackstock, 2005; Zapata et al., 2011; Ruiz-Ballesteros, 2011), questões que se apresentam nos elementos "Dominialidade" e “Organização Comunitária” de Fabrino, Nascimento e Costa (2016).

A colaboração para o planejamento do turismo comunitário é um processo de tomada de decisão conjunta entre as principais partes interessadas autônomas de uma comunidade interorganizacional do destino turístico para gerenciar questões relacionadas ao planejamento e desenvolvimento do destino (Jamal \& Getz, 1995). O TBC reúne, portanto, experiências localizadas dentro de uma comunidade, que geram benefícios para os comunitários, e estes podem influenciar os processos de tomada de decisão dos empreendimentos a serem fomentados (Zapata et al., 2011).

No entanto, "os desequilíbrios de poder e questões de legitimidade relacionadas às partes interessadas podem inibir tanto a iniciação, quanto o sucesso de uma colaboração" (Jamal \& Getz, 1995, p. 190-191). Portanto, Reed (1997) afirma que é importante considerar quem determina quem tem capacidade suficiente para participar, e que a falta de instituições de apoio ao turismo pode permitir que detentores de poder convencionais na comunidade mantenham sua influência nas decisões-chave.

Nesse sentido, Blackstock (2005) destaca três grandes falhas da literatura sobre TBC: a primeira delas está relacionada a uma abordagem funcional do envolvimento da comunidade nos processos de tomada de decisão. Para o autor, "o paradigma do TBC é funcional, pois busca identificar possíveis problemas e superá-los antes que a indústria do turismo seja prejudicada por reações locais. A comunidade é cooptada para apoiar o turismo através de uma ilusão de compartilhamento de poder, mas eles não têm o poder de rejeitar o turismo como uma opção de desenvolvimento" (Blackstock, 2005, p. 41). A segunda falha é o tratamento dado à comunidade anfitriã como um bloco homogêneo, o que leva à ilusão de que o controle local resulta, automaticamente, em tomadas de decisão participativas. A terceira falha é o 
Conti, B. R., Spinola, J. T., \& Saldanha, L. (2021, set./dez.). Turismo de base comunitária: uma revisão sistemática e bibliométrica da literatura

entendimento de que o TBC está diretamente vinculado ao empoderamento dos atores comunitários, uma vez que o mercado de turismo sempre resiste à participação da comunidade nas tomadas de decisões, assim que percebe que isso aumentará os custos e diminuirá os lucros. Assim, na maioria das vezes, a participação do público é reduzida a um processo de legitimação pela aprovação, o que não se configura como uma tomada de decisão participativa local.

Uma comunidade com alto nível de controle e gestão do turismo idealmente teria, entre outras características, estrutura democrática ampla e aberta; processo de tomada de decisão equitativo e eficiente; alto grau de participação individual na tomada de decisão; e grande quantidade de propriedade local; o que, na prática, é raro de se encontrar (Mitchell \& Reid, 2001). Uma possível justificativa para isso é o fato de os operadores de turismo serem percebidos como intermediadores diretos do TBC, ao invés dos próprios atores comunitários. Os operadores deveriam ser vistos como facilitadores e não como agentes do desenvolvimento, uma vez que não têm uma noção prévia das diferentes realidades vivenciadas por cada comunidade, assim como desconhecem as relações de poder já estabelecidas (Wearing \& McDonald, 2002).

É claramente necessário, portanto, que em cada caso específico, os projetos de TBC aprofundem os processos e ampliem os espaços de participação da comunidade, redistribuindo o poder e contribuindo para a criação de capital social e colaboração entre as partes interessadas (Ruiz-Ballesteros, 2011). Discussão já proposta por Reed (1997) ao sugerir as três policy arenas $^{2}$ que seriam essenciais às tomadas de decisão em projetos de TBC, e por Keogh (1990), ao discorrer sobre as necessidades de informação dos residentes de áreas de destino para uma participação mais efetiva no planejamento do turismo comunitário.

Além deste grupo de artigos voltados à discussão da participação, colaboração e relações de poder envolvidas no TBC, as questões da sustentabilidade ambiental e análise do TBC em ambientes naturais aparecem em cinco (41\%) dos 12 artigos internacionais mais relevantes ainda que estes também se dediquem a analisar a participação dos atores locais (Joppe, 1996; Wearing \& McDonald, 2002; Choi \& Sirakaya, 2006; Sebele, 2010; Ruiz-Ballesteros, 2011).

Vale destacar que após a realização de diversos debates e eventos internacionais sobre a superexploração dos recursos naturais e a degradação ambiental, com destaque para a Rio-

\footnotetext{
${ }^{2}$ As policy arenas são espaços de relação de poder e tomadas de decisão para o planejamento do turismo. Segundo o autor trata-se da aplicação da Teoria Organizacional ao turismo, como forma de se buscar compreender como as relações de poder afetam as tentativas de planejamento do turismo comunitário. As três policy arenas tratadas são: "Policy Arena de Desenvolvimento" (nesta arena prevalecem as políticas convencionais de desenvolvimento e a participação de empresários privados, uma vez que as tomadas de decisão são impulsionadas pelo mercado), "Policy Arena de Alocação" (esta arena diz respeito à alocação dos serviços públicos, onde a tomada de decisão é baseada em informações, e quem participa detém o conhecimento dos processos políticos e organizacionais) e "Policy Arena de Organização" (nesta arena a tomada de decisão é compartilhada entre diversos níveis de governo e as diferentes partes interessadas dentre de uma comunidade local) (Reed, 1997).
} 
Conti, B. R., Spinola, J. T., \& Saldanha, L. (2021, set./dez.). Turismo de base comunitária: uma revisão sistemática e bibliométrica da literatura

$92^{3}$, o turismo se consolidou como alternativa dos governos para implantação do almejado "desenvolvimento sustentável"4. Nesse contexto, considerando a pressão dos movimentos ambientalistas em ascensão e a demanda de organismos internacionais, o ecoturismo passou a figurar como uma das principais alternativas às formas tradicionais de planejamento do turismo, sobretudo em áreas naturais protegidas.

Para a Sociedade Internacional do Ecoturismo (International Ecoturism Society - TIES, 1990) este é definido como viagem responsável a áreas naturais conservadas que propiciam o bem-estar da população local. "Ecoturismo, em outras palavras, envolve tanto um sério compromisso com a natureza como responsabilidade social. Essa responsabilidade deve ser assumida também pelo viajante. A expressão viagem responsável, outra designação para ecoturismo, envolve objetivos semelhantes" (Western, 1995, p.17). O ecoturismo deve, portanto, satisfazer três critérios: 1) as atrações devem ser predominantemente baseadas na natureza, 2) as interações do visitante com essas atrações devem estar focadas na aprendizagem ou educação ambiental, e 3) a gestão de produtos deve seguir princípios e práticas associadas à sustentabilidade ecológica, sociocultural e econômica (Blamey, 1997).

Assim, ainda que na década de 1990 já tenha havido o reconhecimento de que os esforços para tornar o turismo "uma opção mais sustentável" deveriam ser ampliados e se concentrar cada vez mais na abordagem do desenvolvimento comunitário (Joppe, 1996), os artigos deste grupo foram publicados majoritariamente no século XXI.

Nesse cenário, Wearing e McDonald (2002) se dedicam ao entendimento teórico sobre as abordagens de base comunitária aplicadas ao ecoturismo e, mais especificamente, ao papel que os intermediários desempenham nestas relações. Já Choi e Sirakaya (2006) partem para a formulação de 26 indicadores para medir o desenvolvimento do turismo comunitário dentro de uma estrutura sustentável. Consideram, portanto, que o "desenvolvimento sustentável do turismo comunitário" deve ter como objetivo a melhoria da qualidade de vida dos residentes a partir da otimização de benefícios para a economia local, da proteção aos ambientes naturais e construídos, e da promoção de uma experiência de alta qualidade aos visitantes. Os autores afirmam que embora a maioria dos índices de monitoramento disponíveis foquem em aspectos

\footnotetext{
${ }^{3}$ A Conferência das Nações Unidas sobre Meio Ambiente e Desenvolvimento, também conhecida como Rio-92, foi realizada na cidade do Rio de Janeiro/Brasil, em 1992. Pautou a necessidade de união entre as nações em prol da construção de uma sociedade mais sustentável e a urgência de minimização dos riscos associados à exploração ilimitada da natureza.

${ }^{4}$ Termo cunhado pela Comissão Mundial sobre Desenvolvimento e Meio Ambiente e publicado no Relatório Brundtland, em 1987. Segundo o Relatório, Desenvolvimento Sustentável é: "o desenvolvimento que encontra as necessidades atuais sem comprometer a habilidade das futuras gerações de atender suas próprias necessidades [...] O desenvolvimento sustentável requer que as sociedades atendam às necessidades humanas tanto pelo aumento do potencial produtivo como pela garantia de oportunidades iguais para todos [...] Na sua essência, o desenvolvimento sustentável é um processo de mudança no qual a exploração dos recursos, o direcionamento dos investimentos, a orientação do desenvolvimento tecnológico e a mudança institucional estão em harmonia e reforçam o atual e futuro potencial para satisfazer as aspirações e necessidades humanas (BRUNDTLAND, 1987).
} 
econômicos, físicos e ecológicos dominantes, o estudo em questão se diferencia ao ampliar o espectro incluindo aspectos sociais, culturais, tecnológicos e políticos.

Sebele (2010), por sua vez, trata do gerenciamento de recursos naturais de base comunitária, baseando-se na teoria da gestão de propriedades comuns, que desencoraja o gerenciamento de recursos de acesso aberto, para propor a propriedade, gerenciamento, controle e uso desses recursos pelas comunidades locais. Por fim, Ruiz-Ballesteros (2011) se dedica ao estudo da resiliência socioecológica nas experiências de TBC. E tais experiências são também retratadas como caminhos para se alcançar o desenvolvimento sustentável das comunidades.

Essas duas grandes linhas de pesquisa identificadas no TBC (a da participação/colaboração e a da sustentabilidade), foram também relatadas na publicação de Graciano e Holanda (2020), apesar de esse estudo contemplar uma quantidade menor de artigos em língua inglesa e incluir os artigos publicados em revistas brasileiras. Os autores afirmam que "o principal tema na maioria dos artigos girou acerca da participação da comunidade, corroborado por estudos como os de Kibicho (2008) e Okazaki (2008) que apontam a participação como elemento essencial para o TBC" e que a "a sustentabilidade foi amplamente debatida no recorte, pois como lembraram Dangi e Jamal (2016) ela possui uma proximidade com o TBC em definições, critérios e princípios, como já abordaram Irving e Azevedo (2002) e Sampaio e Coriolano (2009)" (Graciano \& Holanda, 2020, p. 173).

Na seção a seguir serão apresentados os resultados da análise bibliométrica, a análise qualitativa dos corpus textuais dos artigos selecionados, assim como as metodologias e estudos de caso existentes.

\section{Resultados e discussão}

A partir da análise bibliométrica dos 330 artigos recuperados na base Scopus, é possível identificar que o primeiro artigo sobre TBC publicado data de 1983, com o título "Public participation in community tourism planning: a gaming simulation approach". O artigo, de autoria de Philippos J. Loukissas (Departamento de Planejamento Urbano e Regional da Universidade Estadual da Pensilvânia/EUA), foi publicado no periódico Journal of Travel Research, e sugere a simulação de jogos como uma ferramenta para reunião e análise de informações públicas para o processo de planejamento e gerenciamento do turismo comunitário. 
Conti, B. R., Spinola, J. T., \& Saldanha, L. (2021, set./dez.). Turismo de base comunitária: uma revisão sistemática e bibliométrica da literatura

No entanto, apenas recentemente o TBC vem alcançando alguma projeção como tema de publicação nos periódicos internacionais, como evidenciado na Figura a seguir:

\section{Figura 1}

Gráfico de Evolução das Publicações Sobre TBC

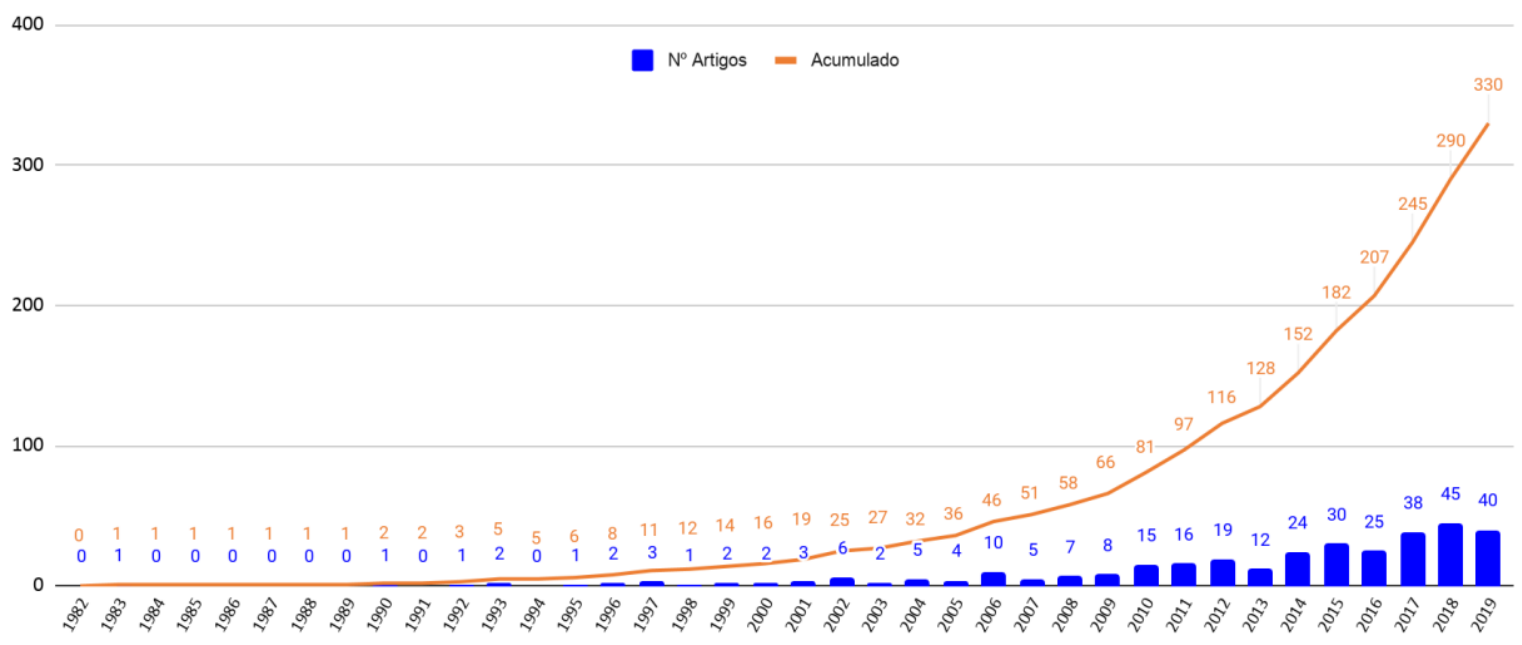

Fonte: Elaboração própria a partir dos dados disponíveis na base Scopus (2019).

É possível perceber, na figura anterior, que o ano de 2018 foi o mais relevante para as publicações sobre TBC, mas desde 2014 parece haver um crescimento do interesse dos pesquisadores sobre o tema. Vale destacar, no entanto, que este levantamento não foi capaz de representar as publicações em língua espanhola e portuguesa. Apesar dos termos de busca terem sido considerados nesses idiomas, o resultado encontrado foi irrelevante e não retrata o quantitativo de pesquisas e artigos sobre TBC produzidos em português e espanhol (Tabela 2).

Tal afirmativa pode ser corroborada a partir de um teste de pesquisa realizado na base "Publicações de Turismo", , da Universidade de São Paulo (USP), que contempla artigos publicados em periódicos científicos iberoamericanos de Turismo que utilizam o sistema Open Journal System (OJS). Foram encontrados nesta base 126 artigos em português para o termo "turismo de base comunitária" e 78 artigos para o termo "turismo comunitário". Já em espanhol, foi possível identificar 68 artigos no total (20 para o termo "turismo de base comunitaria" e 48 para o termo "turismo comunitario"). No entanto, é possível inferir que estes artigos estão publicados em revistas de menor relevância científica, uma vez que não estão indexadas às

\footnotetext{
${ }^{5}$ Disponível em: http://www.each.usp.br/turismo/publicacoesdeturismo/sobre.php
} 
Conti, B. R., Spinola, J. T., \& Saldanha, L. (2021, set./dez.). Turismo de base comunitária: uma revisão sistemática e bibliométrica da literatura

principais bases de busca internacionais. Estes artigos não alcançam, portanto, a comunidade acadêmica mais ampla, mas podem ser importantes para uma análise específica sobre a realidade do TBC nos países ibero-americanos, sendo este um enfoque de pesquisa que poderá ser desenvolvido em outro estudo.

Com relação ao predomínio dos artigos sobre TBC nos últimos anos, é possível entender que esta temática se faz cada vez mais importante diante das inúmeras pesquisas e publicações que evidenciam impactos negativos do modelo de turismo vigente, sejam eles impactos sob a base de recursos naturais; sob as formas de organização e socialização de determinadas sociedades ou grupos; ou até mesmo os impactos resultantes do atualmente discutido overtourism. O overtourism é descrito por Koens et al. (2018) como um problema social oriundo do impacto negativo excessivo do turismo nas comunidades receptoras ou ambientes naturais. Assim, o TBC vem sendo entendido como alternativa ao turismo de massa ou como uma nova forma de se pensar e realizar o turismo, sendo marcado pelo "encontro" entre o visitante e a população local, e tendo como base uma relação de compartilhamento e aprendizagem mútua (Conti et al., 2018).

Dentre os 134 periódicos em que os artigos em questão foram publicados, destacam-se os seguintes (Tabela 3). Nos demais periódicos, o número de artigos publicados sobre o tema é menor que dez (Figura 2), sendo que em 103 (78\%) periódicos foram publicados apenas um ou dois artigos em toda a série histórica.

\section{Tabela 3}

Periódicos com Maior número de Artigos Sobre TBC

\begin{tabular}{|c|c|c|c|}
\hline Periódico & País do Periódico & $\mathbf{N}^{\mathbf{0}}$ de artigos & $\begin{array}{c}\text { \% total dos artigos } \\
\text { publicados }\end{array}$ \\
\hline $\begin{array}{c}\text { Journal of Sustainable Tourism } \\
\begin{array}{c}\text { African Journal of Hospitality, } \\
\text { Tourism and Leisure }\end{array}\end{array}$ & Reino Unido & 30 & 9.09 \\
\hline Aurrent Issues in Tourism & Reino Unido & 22 & 6.67 \\
\hline Tourism Management & Reino Unido & 11 & 3.33 \\
\hline Tourism Planning and Development & Reino Unido & 11 & 3.33 \\
\hline Annals of Tourism Research & Reino Unido & 10 & 3.33 \\
\hline Tourism Geographies & Reino Unido & 10 & 3.03 \\
\hline
\end{tabular}

Fonte: Elaboração própria a partir dos dados disponíveis na base Scopus (2019). 
Conti, B. R., Spinola, J. T., \& Saldanha, L. (2021, set./dez.). Turismo de base comunitária: uma revisão sistemática e bibliométrica da literatura

\section{Figura 2}

Gráfico com Quantitativo de Artigos Publicados por Periódico

30
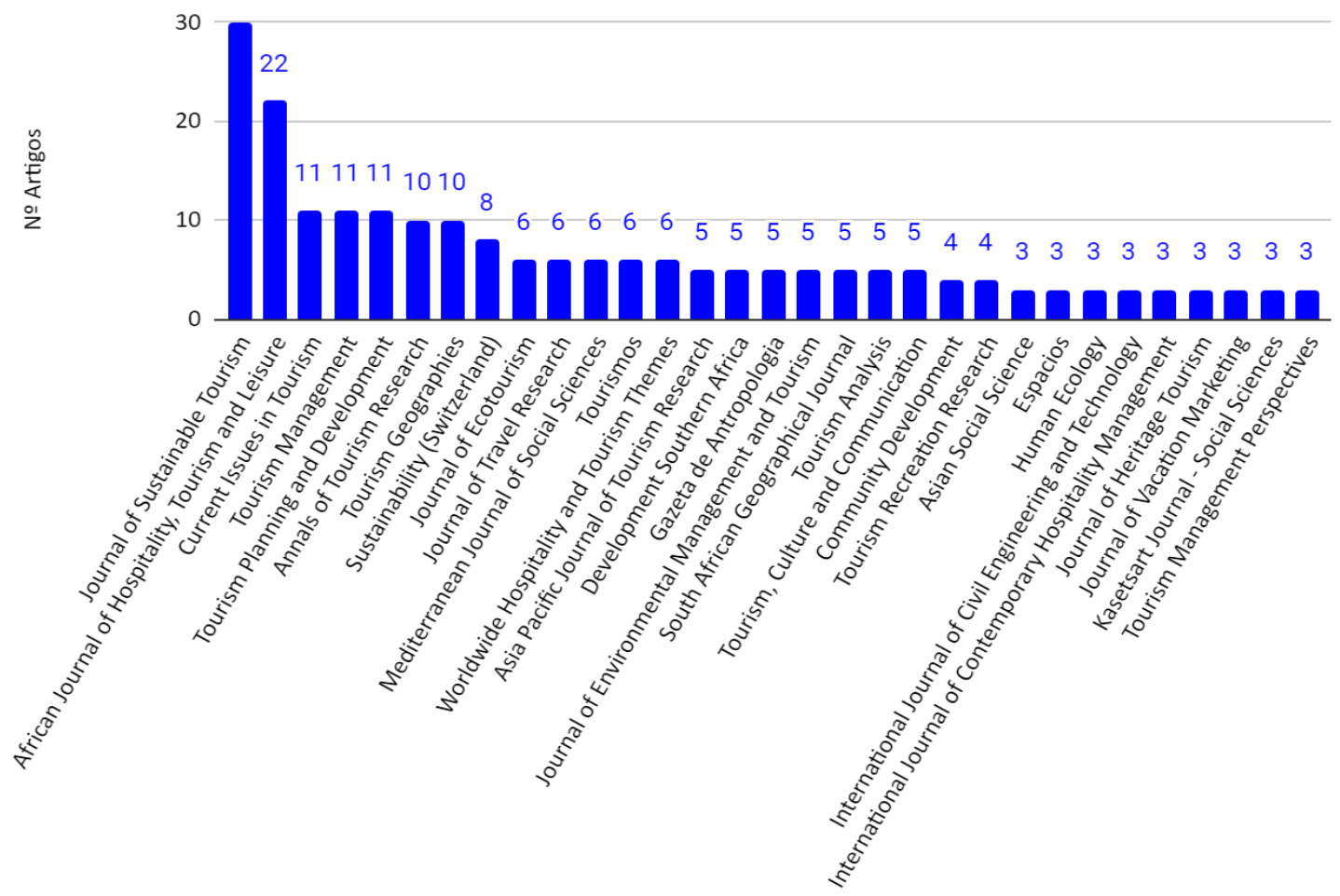

Fonte: Elaboração própria a partir dos dados disponíveis na base Scopus (2019).

É interessante observar que o periódico com o maior número de publicações sobre TBC está associado à área de sustentabilidade. O Journal of Sustainable Tourism tem por objetivo avançar no entendimento crítico acerca das relações existentes entre turismo e sustentabilidade, com foco em pesquisas interdisciplinares e trabalhos holísticos e integrativos. Dessa forma, o tema do TBC se enquadra na perspectiva do periódico, principalmente ao se levar em consideração que as pesquisas nesta área já evidenciaram o TBC como alternativa de desenvolvimento do turismo mais alinhada às premissas da sustentabilidade (econômica, social, cultural, ambiental e política). Além disso, estes estudos dependem, na maioria das vezes, de uma visão holística sobre o contexto no qual a experiência se concretiza e sobre os atores envolvidos no seu gerenciamento.

O segundo principal periódico é o African Journal of Hospitality, Tourism and Leisure, o que pode ser justificado pelo elevado número de artigos que compreendem estudos de caso de destinos localizados no continente africano, principalmente a África do Sul. Esta análise será melhor apresentada e discutida posteriormente. 
Conti, B. R., Spinola, J. T., \& Saldanha, L. (2021, set./dez.). Turismo de base comunitária: uma revisão sistemática e bibliométrica da literatura

Com relação aos artigos mais citados (Tabela 4), estes foram publicados nos periódicos Annals of Tourism Research e Tourism Management.

\section{Tabela 4}

Artigos de Maior Relevância Acadêmica

\begin{tabular}{|c|c|c|c|}
\hline Nome do Artigo & Autores & Periódico & $\mathrm{N}^{0}$ citações \\
\hline $\begin{array}{l}\text { 1. Collaboration theory and community } \\
\text { tourism planning }\end{array}$ & $\begin{array}{l}\text { Jamal T.B., } \\
\text { Getz D. }\end{array}$ & $\begin{array}{l}\text { Annals of Tourism } \\
\text { Research }\end{array}$ & 742 \\
\hline $\begin{array}{l}\text { 2. Sustainability indicators for managing } \\
\text { community tourism }\end{array}$ & $\begin{array}{c}\text { Choi H.C., Sirakaya } \\
\text { E. }\end{array}$ & Tourism Management & 388 \\
\hline $\begin{array}{l}\text { 3. Power relations and community-based } \\
\text { tourism planning }\end{array}$ & Reed M.G. & $\begin{array}{l}\text { Annals of Tourism } \\
\text { Research }\end{array}$ & 251 \\
\hline 4. A critical look at community-based tourism & Blackstock K. & $\begin{array}{c}\text { Community } \\
\text { Development Journal }\end{array}$ & 180 \\
\hline $\begin{array}{l}\text { 5. Public participation in community tourism } \\
\text { planning }\end{array}$ & Keogh B. & $\begin{array}{l}\text { Annals of Tourism } \\
\text { Research }\end{array}$ & 164 \\
\hline 6. A tale of tourism in two cities & Madrigal R. & $\begin{array}{l}\text { Annals of Tourism } \\
\text { Research }\end{array}$ & 156 \\
\hline $\begin{array}{l}\text { 7. Community integration. Island tourism in } \\
\text { Peru }\end{array}$ & $\begin{array}{l}\text { Mitchell R.E., Reid } \\
\text { D.G. }\end{array}$ & $\begin{array}{l}\text { Annals of Tourism } \\
\text { Research }\end{array}$ & 155 \\
\hline $\begin{array}{l}\text { 8. Sustainable community tourism } \\
\text { development revisited }\end{array}$ & Joppe M. & Tourism Management & 136 \\
\hline $\begin{array}{l}\text { 9. Community-based tourism ventures, } \\
\text { benefits and challenges: Khama Rhino } \\
\text { Sanctuary Trust, Central District, Botswana }\end{array}$ & Sebele L.S. & Tourism Management & 123 \\
\hline $\begin{array}{c}\text { 10. Can community-based tourism contribute } \\
\text { to development and poverty alleviation? } \\
\text { Lessons from Nicaragua }\end{array}$ & $\begin{array}{l}\text { Zapata M.J., } \\
\text { Hall C.M., } \\
\text { Lindo P., } \\
\text { Vanderschaeghe M. }\end{array}$ & $\begin{array}{l}\text { Current Issues in } \\
\text { Tourism }\end{array}$ & 118 \\
\hline $\begin{array}{l}\text { 11. The development of community-based } \\
\text { tourism: Re-thinking the relationship between } \\
\text { tour operators and development agents as } \\
\text { intermediaries in rural and isolated area } \\
\text { communities }\end{array}$ & $\begin{array}{l}\text { Wearing S., } \\
\text { McDonald M. }\end{array}$ & $\begin{array}{c}\text { Journal of } \\
\text { Sustainable Tourism }\end{array}$ & 114 \\
\hline $\begin{array}{l}\text { 12. Social-ecological resilience and } \\
\text { community-based tourism. An approach from } \\
\text { Agua Blanca, Ecuador. }\end{array}$ & Ruiz-Ballesteros E. & Tourism Management & 102 \\
\hline
\end{tabular}

Fonte: Elaboração própria a partir dos dados disponíveis na base Scopus (2019). 
Conti, B. R., Spinola, J. T., \& Saldanha, L. (2021, set./dez.). Turismo de base comunitária: uma revisão sistemática e bibliométrica da literatura

O artigo mais citado data de 1995 e foi escrito por pesquisadores canadenses com o objetivo de aplicar os construtos teóricos da colaboração aos destinos turísticos, oferecendo insights sobre a colaboração interorganizacional para o planejamento e o desenvolvimento de destinos turísticos locais e comunitários. Proposições são apresentadas para orientar iniciativas colaborativas e para investigar a aplicação da teoria da colaboração ao planejamento de destinos turísticos. Outros quatro artigos datam da década de 1990 (n. 3, 5, 6 e 8) e são direcionados ao entendimento sobre as relações de poder e os processos de participação dos atores comunitários no planejamento e organização do TBC em dado território; suas percepções sobre esses processos e sobre os impactos do turismo; e sobre como ocorre a repartição dos benefícios econômicos advindos das práticas de TBC (geração de renda e desenvolvimento econômico).

Denota-se que, a partir da realização da Rio-92, como já mencionado anteriormente, caminhos alternativos para o desenvolvimento do turismo passaram a fazer parte das discussões internacionais e das agendas de políticas públicas dos países. Estes caminhos visam a redução dos impactos negativos do turismo sobre a base de recursos naturais, as culturas locais e a organização da vida nas comunidades receptoras, principalmente aquelas localizadas em áreas protegidas. A Rio-92, assim como sua repercussão a nível mundial, pode ter sido ponto de partida para que questões relativas à sustentabilidade ambiental e à participação social passassem a fazer parte de projetos/discussões/políticas públicas de diversas áreas, dentre elas o turismo. Este evento teve ainda como um de seus principais desdobramentos a assinatura da Convenção da Diversidade Biológica (CDB), primeiro documento mundial a alertar para a necessidade de proteção do conhecimento tradicional das comunidades e de criação de sistemas de áreas protegidas. Assim, o século XXI tem início com a premissa da sustentabilidade, da conservação in situ da diversidade biológica e da repartição justa e equitativa dos benefícios derivados da utilização dos recursos e ambientes naturais.

Dos 12 artigos de maior relevância analisados nesta pesquisa, sete foram publicados após os anos 2000. O segundo mais citado data de 2006, é derivado da parceria de um autor canadense e outro norte-americano, e teve por objetivo a construção de indicadores para medir o desenvolvimento do turismo comunitário, considerando a sustentabilidade como enquadramento geral. Os demais apresentam avaliações sobre o TBC em determinados destinos (estudos de caso), com identificação de desafios e/ou proposição de caminhos. 
Os autores desses artigos de maior relevância são predominantemente da América do Norte (Canadá e Estados Unidos). No entanto, ao se analisar os autores ${ }^{6}$ com maior número de artigos publicados sobre TBC (Tabela 5), dois assumem a liderança no ranking: Andrea Giampiccoli, do Departamento de Hospitalidade e Turismo da Universidade Tecnológica de Durban (África do Sul), e Oliver Mtapuri, da Escola de Ambiente Construído e Estudos de Desenvolvimento da Universidade de KwaZulu-Natal (África do Sul). Vale destacar que considerando os 330 artigos analisados, foram identificados cerca de 70 estudos de caso localizados na África, o que pode justificar a importância dos pesquisadores africanos no rol de publicações internacionais sobre TBC. Em terceiro lugar está Esteban Ruiz-Ballesteros, do Departamento de Antropologia Social, Psicologia e Saúde Pública da Universidade Pablo de Olavide (Sevilla/Espanha).

\section{Tabela 5}

Principais Autores Por Quantidade de Artigos Publicados Sobre TBC

\begin{tabular}{|c|c|c|}
\hline Autor & Instituição / País & $\mathbf{N}^{\mathbf{0}}$ de artigos publicados \\
\hline Giampiccoli A. & Universidade Tecnológica de Durban/África do Sul & 19 \\
\hline Mtapuri O. & Universidade de Kwazulu-Natal/África do Sul & 6 \\
\hline Ruiz-Ballesteros E. & Universidade Pablo de Olavide/Espanha & 5 \\
\hline Saarinen J. & Universidade de Oulu/Finlândia & 5 \\
\hline Saayman M. & Universidade do Noroeste/África do Sul & 4 \\
\hline Lenao M. & Universidade do Botsuana/Botsuana & 3 \\
\hline Ellis S. & Universidade de Wollongong/Austrália & 3 \\
\hline Henama U.S. & Universidade Tecnológica de Tshwane/África do Sul & 3 \\
\hline Mangope D. & Universidade do Estado Livre/África do Sul & 3 \\
\hline Mbaiwa J.E. & Universidade do Botsuana/Botsuana & 3 \\
\hline Reid D.G. & Universidade de Guelph/Canadá & 3 \\
\hline Strydom A.J. & Universidade Tecnológica Central/África do Sul & \\
\hline
\end{tabular}

Fonte: Elaboração própria a partir dos dados disponíveis na base Scopus (2019).

Ao analisar a rede de coautoria dos autores com maior número de artigos publicados sobre TBC (Tabela 5), chega-se a um total de 31 coautores de oito países diferentes (Figura 3 ). A África do Sul é o país com maior número de coautorias identificadas, justamente o país no qual estão sediados os autores com mais publicações: Andrea Giampiccoli e Oliver Mtapuri. Nota-se, na Figura 3, que suas conexões de coautorias são interligadas e possuem maior densidade em comparação aos outros núcleos de coautorias. Destaca-se, também, a internacionalização dos artigos com autores de Botsuana, os quais se relacionam com autores da própria África (África do Sul), Europa (Finlândia) e da América do Norte (Estados Unidos)

${ }^{6}$ Para esta análise foram considerados todos os autores e coautores dos artigos. 
Conti, B. R., Spinola, J. T., \& Saldanha, L. (2021, set./dez.). Turismo de base comunitária: uma revisão sistemática e bibliométrica da literatura

\section{Figura 3}

Rede de coautoria em relação aos principais autores sobre TBC

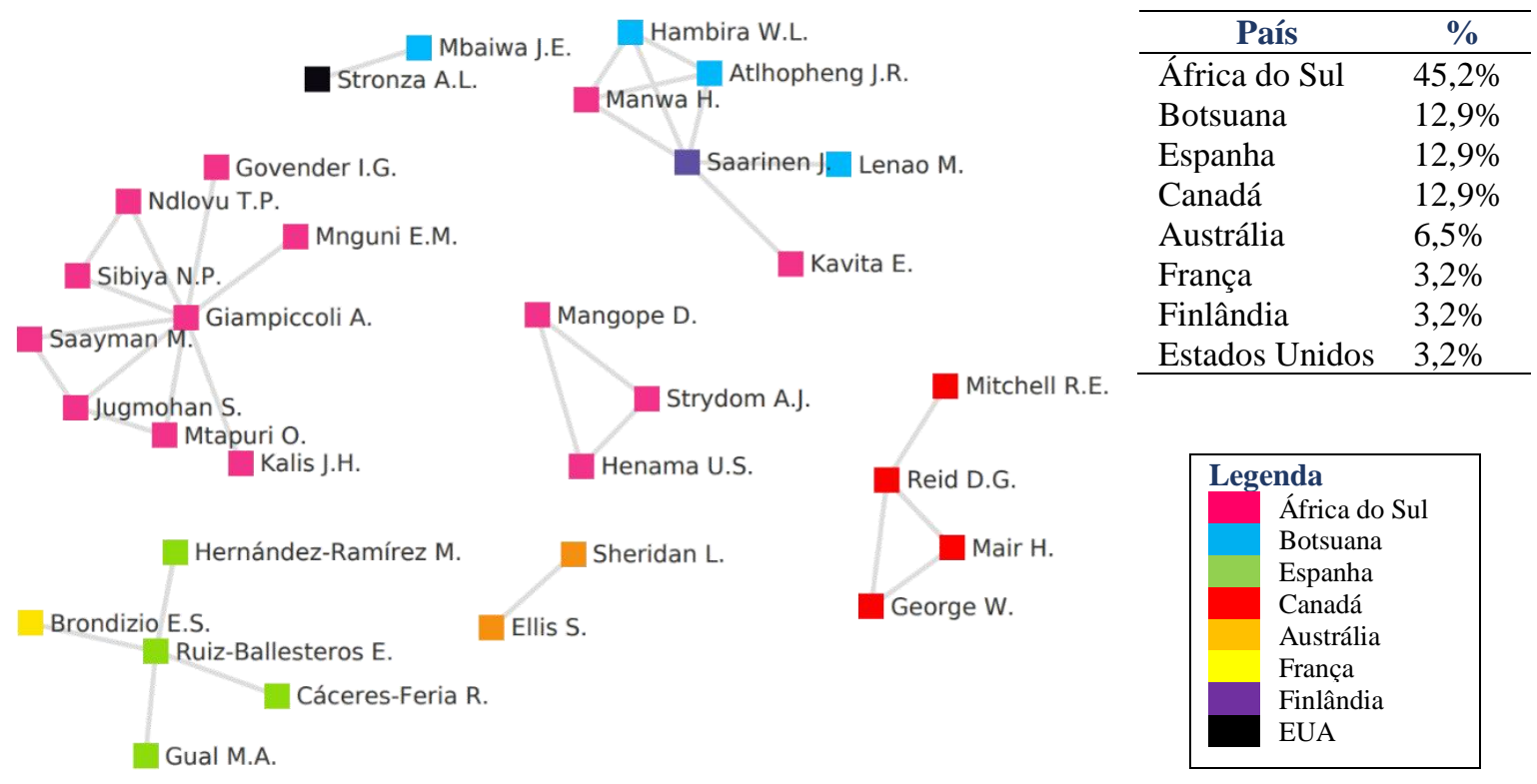

Fonte: Elaboração própria (2019).

Outros 600 autores ou coautores foram identificados, mas com o número de um ou dois artigos sobre TBC cada um. É importante ressaltar que um mesmo artigo foi contabilizado para todos os autores responsáveis por sua publicação, no caso de o artigo contar com mais de uma pessoa em sua autoria.

Partindo para uma análise dos corpus textuais dos artigos selecionados, apresentam-se a seguir a "nuvem de palavras" (Figura 4) e a "análise de similitude" (Figura 5), construídas com o auxílio do Iramuteq e do Gephi. Enquanto a primeira leva em consideração os termos mais recorrentes entre as palavras-chave de cada artigo, a segunda análise considera os termos com maior frequência nos resumos dos artigos identificados.

Para possibilitar um refinamento e maior precisão em relação à comparação entre os resumos e palavras-chave dos artigos investigados, ambas as análises consideraram apenas formas textuais como substantivos comuns, advérbios, adjetivos e verbos. 
Conti, B. R., Spinola, J. T., \& Saldanha, L. (2021, set./dez.). Turismo de base comunitária: uma revisão sistemática e bibliométrica da literatura

Figura 4

Nuvem de Palavras em Relação às Palavras-Chave dos Artigos

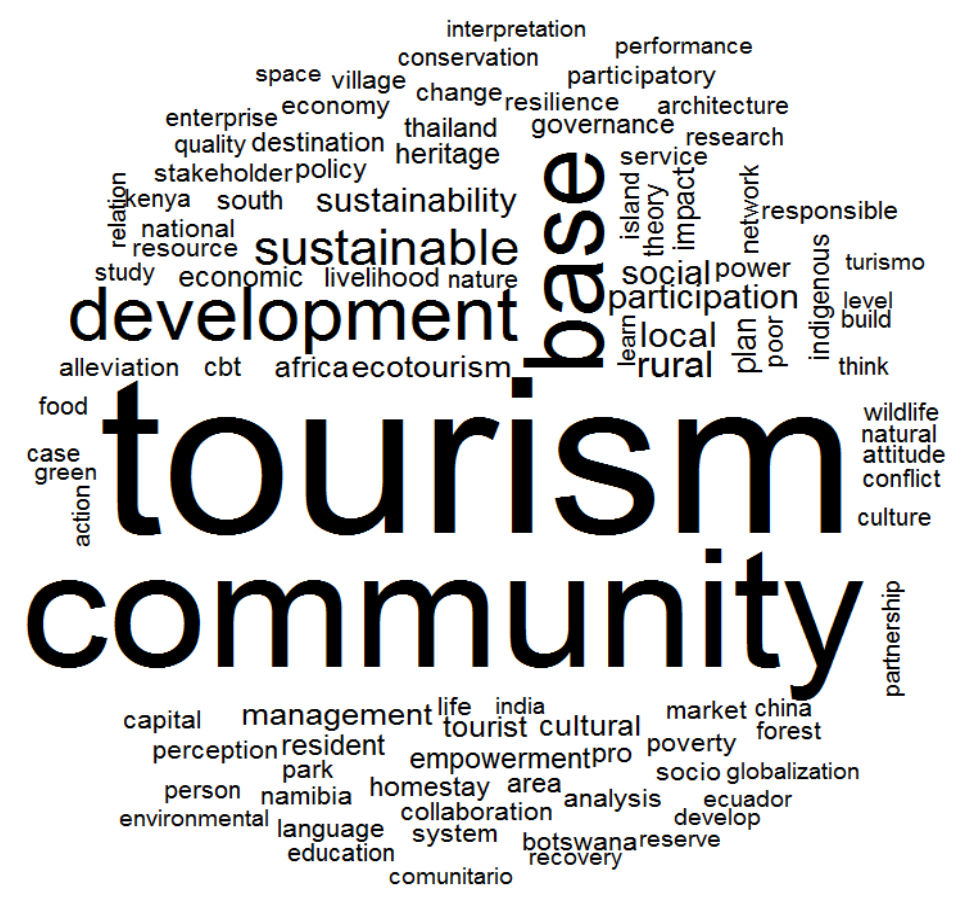

Fonte: Elaboração própria (2019).

Foram delimitados, para a análise em "nuvem de palavras", os 100 termos mais recorrentes entre as palavras-chave de 300 artigos - cerca de $9 \%$ do total de artigos identificados não possuíam palavra-chave em sua composição. Destacam-se os seguintes termos, originalmente em inglês, com tradução nossa: "turismo" (n=318), "comunitário/comunitária" (n=318), "base” ( $\mathrm{n}=181)$, “desenvolvimento" $(\mathrm{n}=114)$, "sustentável” ( $\mathrm{n}=61)$, "rural” $(\mathrm{n}=36)$, "local" (n=29), "participação" (n=28), "sustentabilidade" (n=25), "social” (n=23).

É possível verificar que o tamanho da fonte de cada termo é diretamente proporcional à respectiva frequência do termo nos artigos analisados. Além dos termos que contemplam as expressões “community-based tourism" e "community tourism”, estas se associam aos conceitos de desenvolvimento sustentável e sustentabilidade, principalmente a nível local e em ambientes rurais - fato que retrata a contextualização de grande parte dos estudos de caso contemplados nesses artigos. Apesar do termo "desenvolvimento sustentável” ser bastante discutido no âmbito da academia, este ainda prevalece para descrever os casos classificados como de turismo comunitário, isso porque o TBC é percebido como uma via alternativa de desenvolvimento do turismo, não mais nos moldes de um turismo de massas. E este turismo parece ser mais 
Conti, B. R., Spinola, J. T., \& Saldanha, L. (2021, set./dez.). Turismo de base comunitária: uma revisão sistemática e bibliométrica da literatura

promissor em ambientes com um menor número de atores (stakeholders), dada a sua escala limitada, e em ambientes rurais.

A “nuvem de palavras" evidencia, também, a importância da participação social no TBC, expressão que associada aos termos "plano" (n=22) e "gestão" (n=19), que sucedem o quantitativo de frequências, traduz a necessidade de um planejamento estratégico do TBC de forma colaborativa e alinhada aos interesses locais. Outras palavras que também podem representar este enfoque são: poder, governança, participativa, rede, parceria, empoderamento, colaboração. Como já discutido na seção anterior deste artigo a colaboração, o protagonismo das comunidades e as relações de poder são discussões prementes para os pesquisadores do TBC, a nível nacional e internacional, o que se confirma a partir da nuvem de palavras apresentada.

Em menor quantidade, destacam-se ainda os termos associados às áreas naturais (ecoturismo, parque, natural, natureza, vida selvagem, floresta, meio ambiente, ambiental, recursos naturais, verde). Como os autores apresentam distintas palavras para tratar o TBC associado às áreas naturais, em um primeiro momento esta discussão pode não parecer uma das mais relevantes, mas ao identificar as palavras com sentido semelhante, as pesquisas centradas nesse tema ganham importância, isso porque muitas das experiências analisadas pelos autores se passam em áreas naturais protegidas, com destaque para os parques. Tal percepção é também confirmada na seção anterior, quando da análise dos artigos internacionais de maior relevância.

Com relação especificamente à utilização do termo "ecoturismo", é importante salientar que, para um grupo de autores, o TBC quando realizado em áreas naturais se configura enquanto prática de ecoturismo (ou ecoturismo de base comunitária). Porém, outros autores se utilizam do termo exatamente para criticar esta correlação entre TBC e ecoturismo, entendendo que este último diz respeito a atividades de mercado que não necessariamente se alinham aos princípios de proteção da natureza, sustentabilidade ambiental, envolvimento comunitário, inclusão social. 
Conti, B. R., Spinola, J. T., \& Saldanha, L. (2021, set./dez.). Turismo de base comunitária: uma revisão sistemática e bibliométrica da literatura

\section{Figura 5}

Análise de Similitude dos Termos Recorrentes nos Resumos dos Artigos

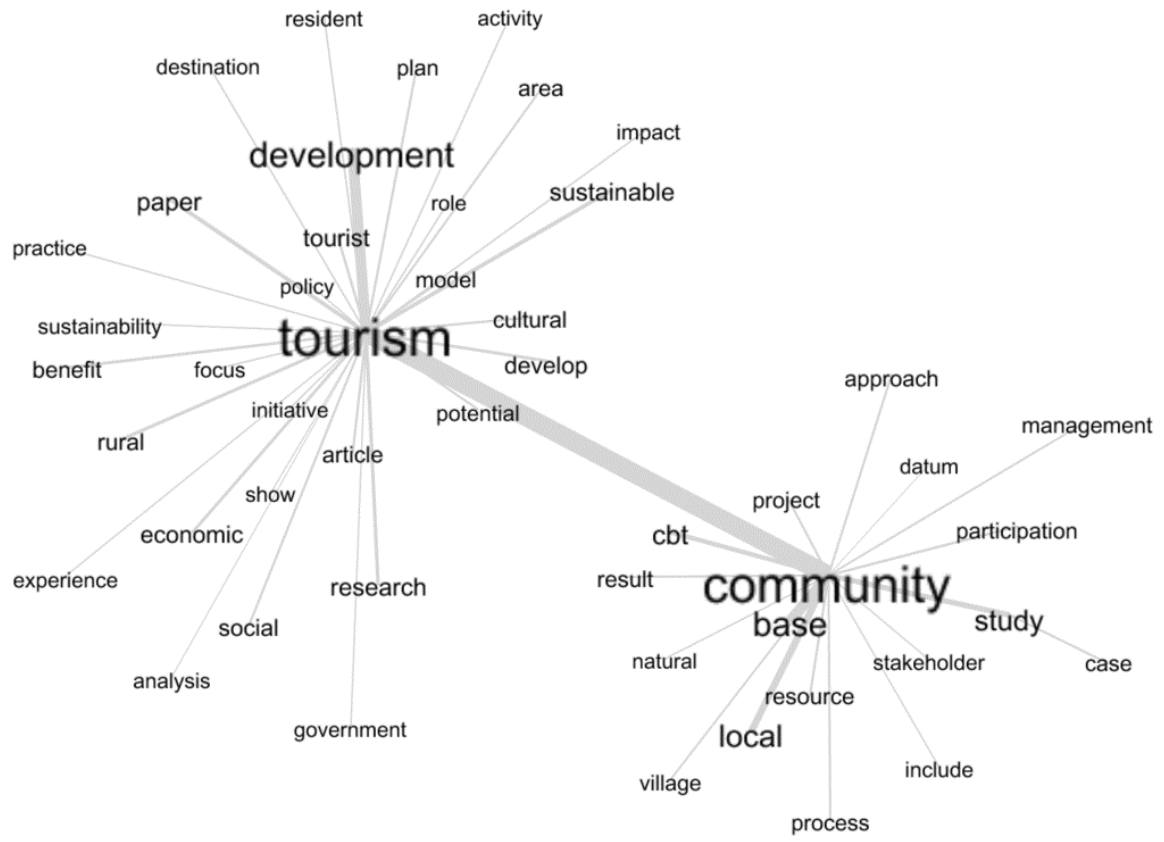

Fonte: Elaboração própria (2019).

A "análise de similitude", caracterizada pela representação da conectividade entre os termos em forma de grafos, delimitou-se aos 50 termos mais recorrentes em todos os 330 resumos, para simplificação dos aspectos visuais. A alteração no tamanho da fonte de cada termo na Figura 5 se dá pela mesma dinâmica relacionada às frequências observadas na análise em "nuvem de palavras".

Ressalta-se, no entanto, a escala de grandeza de ocorrências para os 10 termos mais frequentes: "turismo" ( $\mathrm{n}=1.067)$, “comunitário/comunitária" $(\mathrm{n}=1.011)$, "desenvolvimento" $(n=530)$, "base" $(n=487)$, "local" $(n=386)$, "estudo" $(n=318)$, "TBC" $(n=262)$, "artigo" (n=207), “pesquisa” ( $\mathrm{n}=187)$, “sustentável” $(\mathrm{n}=185)$. Os termos são originalmente em inglês, com tradução nossa.

Notam-se, na Figura 5, dois grupos de relacionamentos entre os termos identificados. No primeiro deles, a conexão do termo "turismo" aos termos alinhados à dinâmica do desenvolvimento sustentável, econômico, social, cultural e rural demonstram sua centralidade no âmbito do planejamento, das políticas, das práticas, das atividades e das pesquisas e metodologias de análise do turismo. No segundo grupo de relacionamento, tem-se o termo 
Conti, B. R., Spinola, J. T., \& Saldanha, L. (2021, set./dez.). Turismo de base comunitária: uma revisão sistemática e bibliométrica da literatura

"comunidade" se relacionando diretamente às perspectivas da inclusão de atores locais na participação de projetos e gestão dos processos de implementação do TBC.

Partindo para uma análise mais qualitativa, a partir da leitura dos 330 resumos dos artigos selecionados, assim como a leitura na íntegra dos artigos mais citados $(n=12)$, foi possível criar categorias de enquadramento desses artigos, levantar os estudos de caso realizados, assim como identificar as metodologias utilizadas pelos autores dos artigos com maior número de citações.

Para o enquadramento da totalidade dos artigos, foram criadas sete categorias, apresentadas e discutidas na Tabela 6, a seguir. Vale destacar que novamente fica evidente a recorrência das discussões que envolvem a participação/gestão comunitária, a percepção dos atores locais e os processos de distribuição de benefícios e inclusão social. Em menor quantidade estão os artigos teóricos e aqueles que focam na análise do turista que busca por destinos/experiências de TBC. Há ainda um número menor destinado a entender o papel das políticas públicas e dos atores externos que apoiam iniciativas de turismo comunitário.

\section{Tabela 6}

Categoria de Enquadramento dos Artigos

\begin{tabular}{|c|c|c|}
\hline Categoria & $\begin{array}{l}\mathrm{N}^{0} \text { de } \\
\text { artigos }\end{array}$ & Descrição \\
\hline $\begin{array}{c}\text { Avaliação do } \\
\text { desenvolvimento do TBC }\end{array}$ & 103 & $\begin{array}{l}\text { Artigos que apresentam uma avaliação ampla sobre o desenvolvimento } \\
\text { do TBC em distintos locais, envolvendo aspectos econômicos e/ou } \\
\text { socioculturais e/ou ambientais, e por vezes indicando estratégias de } \\
\text { ação. Estes artigos visam dar conta da realidade complexa e } \\
\text { multifacetada do TBC em determinada realidade. }\end{array}$ \\
\hline $\begin{array}{l}\text { Participação dos atores } \\
\text { comunitários }\end{array}$ & 93 & $\begin{array}{c}\text { Artigos que focam na descrição e análise dos processos participativos } \\
\text { em dadas experiências de TBC, ou seja, em como ocorre a participação } \\
\text { dos atores comunitários no planejamento e na organização do TBC, com } \\
\text { destaque para os espaços de tomadas de decisão. }\end{array}$ \\
\hline Teórico & 42 & $\begin{array}{c}\text { Artigos voltados para a discussão das bases teóricas do TBC, } \\
\text { especialmente para os conceitos de TBC, seus princípios e } \\
\text { metodologias. }\end{array}$ \\
\hline $\begin{array}{l}\text { Percepção dos atores } \\
\text { comunitários }\end{array}$ & 36 & $\begin{array}{l}\text { Artigos que buscam compreender o olhar dos atores comunitários sobre } \\
\text { o TBC em dado território, ou seja, a percepção desses atores sobre os } \\
\text { impactos, as mudanças cotidianas, as relações sociais, a economia local. }\end{array}$ \\
\hline $\begin{array}{l}\text { Desenvolvimento } \\
\text { econômico }\end{array}$ & 22 & $\begin{array}{l}\text { Artigos que focam na investigação dos impactos econômicos do TBC, } \\
\text { na repartição dos benefícios econômicos gerados, e na inclusão social } \\
\text { dos atores comunitários pela via do emprego e da renda. }\end{array}$ \\
\hline Percepção dos turistas & 21 & $\begin{array}{c}\text { Artigos que analisam a avaliação e o perfil dos turistas que buscam } \\
\text { experiências de TBC. }\end{array}$ \\
\hline Políticas Públicas & 13 & $\begin{array}{l}\text { Artigos que focam na análise da atuação de instituições governamentais } \\
\text { e do terceiro setor e/ou no impacto de políticas públicas voltadas para o } \\
\text { TBC. }\end{array}$ \\
\hline
\end{tabular}

Fonte: Elaboração própria (2019). 
Vale destacar ainda que alguns temas correlatos ao TBC são recorrentes nos estudos, como, por exemplo, as discussões sobre sustentabilidade, sobre formas alternativas de desenvolvimento do turismo, sobre ecoturismo e sobre turismo rural, o que foi também possível identificar na "nuvem de palavras" e na "análise de similitude". Além disso, dos 330 artigos analisados, $280(85 \%)$ apresentam estudos de caso, o que evidencia que o tema do TBC requer uma análise que contemple as particularidades das realidades em questão e que esses artigos são também utilizados como forma de compartilhar experiências positivas e negativas em curso no mundo, podendo subsidiar processos participativos de planejamento e de elaboração de políticas públicas.

Os estudos de caso estão divididos por continentes da seguinte forma (Figura 6): Ásia (105 estudos de caso), América (77), África (71), Europa (15) e Oceania (5). Os países mais estudados ao redor do mundo são: Tailândia (22), África do Sul (17), Indonésia (16), Malásia (14), Botsuana (12), EUA (11) e Quênia (10).

\section{Figura 6}

\section{Mapa com Distribuição dos Estudos de Caso Sobre TBC}

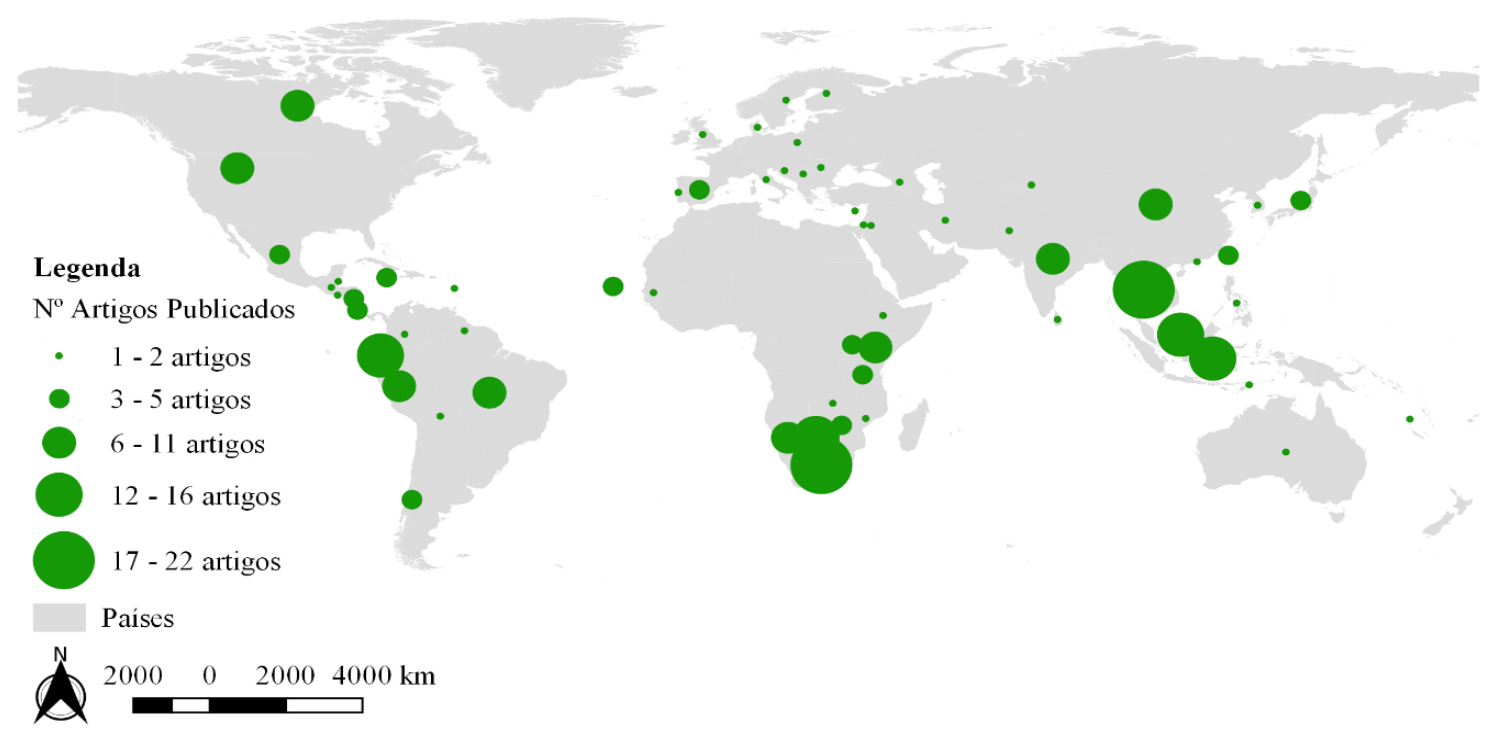

Fonte: Elaboração própria (2019).

Para finalizar a análise pretendida neste artigo, buscou-se identificar as metodologias mais utilizadas pelos autores dos artigos de maior relevância acadêmica $(n=12)$ da amostra selecionada. Constatou-se que nove dos artigos se enquadram como pesquisa qualitativa (75\%) e três se caracterizam como quali-quantitativa (25\%). A seguir estão elencadas as técnicas utilizadas nesses artigos, assim como a categoria de análise em que se encontram. 
Conti, B. R., Spinola, J. T., \& Saldanha, L. (2021, set./dez.). Turismo de base comunitária: uma revisão sistemática e bibliométrica da literatura

\section{Tabela 7}

Metodologias Utilizadas nos Artigos de Maior Relevância Acadêmica

\begin{tabular}{|c|c|c|}
\hline Nome do artigo & Categoria & Técnica \\
\hline $\begin{array}{l}\text { 1. Collaboration theory and } \\
\text { community tourism planning }\end{array}$ & $\begin{array}{l}\text { Avaliação do desenvolvimento do } \\
\text { TBC }\end{array}$ & Análise documental \\
\hline $\begin{array}{l}\text { 2. Sustainability indicators for } \\
\text { managing community tourism }\end{array}$ & Teórico & Realização de grupos focais \\
\hline $\begin{array}{l}\text { 3. Power relations and } \\
\text { community-based tourism } \\
\text { planning }\end{array}$ & $\begin{array}{l}\text { Participação dos atores } \\
\text { comunitários }\end{array}$ & Análise documental \\
\hline $\begin{array}{l}\text { 4. A critical look at community- } \\
\text { based tourism }\end{array}$ & $\begin{array}{l}\text { Avaliação do desenvolvimento do } \\
\text { TBC }\end{array}$ & $\begin{array}{c}\text { Observação; pesquisa participante } \\
\text { e entrevistas }\end{array}$ \\
\hline $\begin{array}{l}\text { 5. Public participation in } \\
\text { community tourism planning }\end{array}$ & $\begin{array}{l}\text { Participação dos atores } \\
\text { comunitários }\end{array}$ & $\begin{array}{l}\text { Análise documental; pesquisa } \\
\text { participante e entrevistas }\end{array}$ \\
\hline 6. A tale of tourism in two cities & Percepção dos atores comunitários & $\begin{array}{c}\text { Análise documental e aplicação de } \\
\text { questionário }\end{array}$ \\
\hline $\begin{array}{l}\text { 7. Community integration. Island } \\
\text { tourism in Peru }\end{array}$ & $\begin{array}{l}\text { Participação dos atores } \\
\text { comunitários }\end{array}$ & $\begin{array}{c}\text { Observação; pesquisa participante } \\
\text { e entrevistas }\end{array}$ \\
\hline $\begin{array}{l}\text { 8. Sustainable community tourism } \\
\text { development revisited }\end{array}$ & Desenvolvimento econômico & Análise documental \\
\hline $\begin{array}{l}\text { 9. Community-based tourism } \\
\text { ventures, benefits and challenges: } \\
\text { Khama Rhino Sanctuary Trust, } \\
\text { Central District, Botswana }\end{array}$ & $\begin{array}{c}\text { Avaliação do desenvolvimento do } \\
\text { TBC }\end{array}$ & $\begin{array}{l}\text { Análise documental; entrevistas; } \\
\text { realização de grupos focais e } \\
\text { aplicação de questionário }\end{array}$ \\
\hline $\begin{array}{l}\text { 10. Can community-based tourism } \\
\text { contribute to development and } \\
\text { poverty alleviation? Lessons from } \\
\text { Nicaragua }\end{array}$ & $\begin{array}{c}\text { Avaliação do desenvolvimento do } \\
\text { TBC }\end{array}$ & $\begin{array}{l}\text { Análise documental e realização } \\
\text { de grupos focais }\end{array}$ \\
\hline $\begin{array}{l}\text { 11. The development of } \\
\text { community-based tourism: Re- } \\
\text { thinking the relationship between } \\
\text { tour operators and development } \\
\text { agents as intermediaries in rural } \\
\text { and isolated area communities }\end{array}$ & $\begin{array}{c}\text { Avaliação do desenvolvimento do } \\
\text { TBC }\end{array}$ & $\begin{array}{c}\text { Observação; pesquisa participante } \\
\text { e entrevistas }\end{array}$ \\
\hline $\begin{array}{l}\text { 12. Social-ecological resilience } \\
\text { and community-based tourism. An } \\
\text { approach from Agua Blanca, } \\
\text { Ecuador. }\end{array}$ & $\begin{array}{l}\text { Avaliação do desenvolvimento do } \\
\text { TBC }\end{array}$ & $\begin{array}{l}\text { Etnografia; observação; } \\
\text { entrevistas, realização de grupos } \\
\text { focais e aplicação de questionário }\end{array}$ \\
\hline
\end{tabular}

Fonte: Elaboração própria (2019). 
Dos artigos destacados anteriormente, as técnicas qualitativas mais recorrentes são análise documental, observação, pesquisa participante, entrevistas e realização de grupos focais. Em apenas um artigo foi utilizado o método etnográfico. Os artigos que apresentam técnicas quantitativas (exclusivamente ou de forma combinada) citam apenas a aplicação de questionários (múltipla escolha) com um contingente maior de respondentes, analisados estatisticamente.

\section{Considerações finais}

Este artigo teve por objetivo realizar uma revisão sistemática da literatura a respeito do estado da arte das pesquisas científicas em TBC, incluindo ainda um estudo bibliométrico sobre essa produção. Foram, portanto, evidenciados aspectos como a evolução temporal das publicações sobre TBC, os artigos com maior número de citações, os principais periódicos e autores da área, as palavras-chave recorrentes, além de uma análise qualitativa sobre os principais temas abordados nos artigos, as metodologias aplicadas e os estudos de caso já realizados.

Os resultados mostram que os primeiros artigos datam da década de 1980, mas a pesquisa em TBC ganha corpo, em número de artigos publicados, na última década. Os dois principais periódicos a dar visibilidade à temática do turismo comunitário são o Journal of Sustainable Tourism e o African Journal of Hospitality, Tourism and Leisure. O primeiro se justifica pelo TBC vir associado a muitas das discussões sobre sustentabilidade no turismo, e o segundo pelo número relevante de pesquisadores do continente africano se dedicando ao tema, apesar dos canadenses e norte-americanos ainda serem maioria.

As principais palavras-chave utilizadas pelos pesquisadores são: turismo comunitário, turismo de base comunitária, desenvolvimento sustentável, desenvolvimento rural, desenvolvimento local, participação e sustentabilidade. Estas palavras já demonstram os principais assuntos/categorias de análise trabalhados pelos pesquisadores, quais sejam: a questão do TBC enquanto caminho alternativo de sustentabilidade na promoção do turismo, o que aparece nos artigos a partir de uma série de estudos de caso; a questão da participação dos atores locais como condição para a existência do projeto de TBC, apesar das diversas dificuldades relatadas; e o viés local como principal âmbito de discussão, com destaque para as problematizações acerca da redistribuição do poder, da cooperação, das arenas de tomada de 
Conti, B. R., Spinola, J. T., \& Saldanha, L. (2021, set./dez.). Turismo de base comunitária: uma revisão sistemática e bibliométrica da literatura

decisão, da repartição de oportunidades e benefícios econômicos. Os artigos se utilizam, em sua maioria, de técnicas qualitativas de pesquisa.

As limitações desta pesquisa derivam do fato de que a base de dados escolhida (Scopus) para identificação da amostra de artigos não contempla um número significativo de publicações em português e espanhol, o que acabou por reduzir grande parte das análises apenas ao contexto dos pesquisadores de língua inglesa ou que se dispuseram a publicar nessa língua. Há a garantia de terem sido escolhidos artigos e periódicos de maior relevância acadêmica, mas pode ter ocorrido a invisibilização das pesquisas brasileiras e de autores ibero-americanos.

Portanto, como futuras indicações de pesquisa, ressalta-se a importância da inclusão de bases que contenham ao menos as principais revistas de turismo de língua portuguesa e espanhola, podendo ser uma opção viável a busca na base Publicações de Turismo ${ }^{7}$, do Programa de Pós-Graduação em Turismo da Escola de Artes, Ciências e Humanidades da USP; ou ainda a análise conjunta dos resultados deste artigo com outros que já avançaram na análise bibliométrica da publicação nacional sobre TBC.

Ainda como indicações de pesquisa ressalta-se o número reduzido de artigos focados em entender a demanda que busca por destinos/experiências de TBC, e o número reduzido de artigos focados no levantamento e discussão de resultados comparativos de políticas públicas de apoio ao TBC. Conforme corroborado por Bravo et al. (2021), a retomada do turismo após a pandemia causada pelo novo coronavírus deve ser orientada a partir da escala humana e não mais pela massificação da atividade turística nos destinos. Assim, o TBC se posiciona como oportunidade de transformação socioeconômica para comunidades locais na constituição de estratégias para o desenvolvimento nacional.

\section{Referências}

Albach, V. M. (2015). A difusão da pesquisa em geografia do turismo na ibero-américa. Tese de Doutorado, Universidade Federal do Paraná, Curitiba, Brasil.

Blackstock, K. (2005). A critical look at community based tourism. Community Development Journal, 40(1), p. 39-49. doi: https://doi.org/10.1093/cdj/bsi005

Blamey, R. (1997). Ecotourism: The search for an operational definition. Journal of Sustainable Tourism, 5, p. 109-130. doi: https://doi.org/10.1080/09669589708667280

${ }^{7}$ Disponível em: http://www.each.usp.br/turismo/publicacoesdeturismo/. 
Conti, B. R., Spinola, J. T., \& Saldanha, L. (2021, set./dez.). Turismo de base comunitária: uma revisão sistemática e bibliométrica da literatura

Bravo, L. L., Macías, N. P. \& Valdés, Z. M. (2021) Turismo comunitario en Ecuador: Apuntes en tiempos de pandemia. Revista de Ciencias Sociales (Ve), 27(1), p. 265275. doi: https://doi.org/10.31876/rcs.v27i1.35312

Busalim, A. H. \& Hussin, A. R. C. (2016). Understanding social commerce: A systematic literature review and directions for further research. International Journal of Information Management, 36(6), p. 1075-1088. doi: https://doi.org/10.1016/j.ijinfomgt.2016.06.005

Bursztyn, I., Bartholo, R. \& Delamaro, M. (2009). Reinventando a reflexão sobre o turismo de base comunitária. IN: Bartholo, R., Sansolo, D. G. \& Bursztyn, I. (Orgs). Turismo de Base Comunitária: diversidade de olhares e experiências brasileiras. Rio de Janeiro: Letra e Imagem, p. 76-91.

Camargo, B. V. (2005). ALCESTE: Um programa informático de análise quantitativa de dados textuais. In Moreira, A. S. P., Camargo, B. V., Jesuíno, J. C. \& Nóbrega, S. M. (Eds.) Perspectivas teórico-metodológicas em representações sociais, João Pessoa: Editora da UFPB, p. 511-539.

Choi, H. C. \& Sirakaya, E. (2006). Sustainability indicators for managing community tourism. Tourism Management, 27, p. 1274-1289. doi:

https://doi.org/10.1016/j.tourman.2005.05.018

Chueke, G. V. \& Amatucci, M. (2015). O que é bibliometria? Uma introdução ao Fórum. Internext, 10(2), p. 1-5. doi: https://doi.org/10.18568/1980-4865.1021-5

Conti, B. R. \& Antunes, D. C. (2020). Turismo e Economia Solidária: uma aproximação relutante. Rosa dos Ventos Turismo e Hospitalidade, 12(1), p. 106-128. doi: http://dx.doi.org/10.18226/21789061.v12i1p106

Conti, B. R., Rocha, L. R. V. G. \& Viteze, N. N. (2018). As conexões entre a economia solidária e o turismo de base comunitária no estado do Rio de Janeiro. Revista Acadêmica Observatório de Inovação do Turismo, 12(2), p. 1-21. doi: https://doi.org/10.17648/raoit.v12n2.5049

Dangi, T. B. \& Jamal, T. (2016). An integrated approach to "sustainable community-based tourism." Sustainability (Switzerland), 8(5). doi: https://doi.org/10.3390/su8050475

Fabrino, N. H., Nascimento, E. P. do \& Costa, H. A. (2016). Turismo de Base comunitária: uma reflexão sobre seus conceitos e práticas. Caderno Virtual de Turismo, Rio de Janeiro, 16(3), p. 172-190. doi: http://dx.doi.org/10.18472/cvt.16n3.2016.1178

Galvão, T. F. \& Pereira, M. G. (2014). Revisões sistemáticas da literatura: Passos para sua elaboração. Epidemiologia e Serviços de Saúde, 23(1), p. 183-184. doi: https://doi.org/10.5123/S1679- 49742014000100018

Ganong, L. H. (1987). Integrative reviews of nursing research. Res Nurs Health. 10(1), p. 111. doi: https://doi.org/10.1002/nur.4770100103 
Conti, B. R., Spinola, J. T., \& Saldanha, L. (2021, set./dez.). Turismo de base comunitária: uma revisão sistemática e bibliométrica da literatura

Graciano, P. F. \& Holanda, L. A. (2020). Análise bibliométrica da produção científica sobre turismo de base comunitária de 2013 a 2018. Revista Brasileira de Pesquisa em Turismo. São Paulo, 14(1), p. 161-179. doi: http://dx.doi.org/10.7784/rbtur.v14i1.1736

Grimm, I. J., Sampaio, C. A. C. \& Garcia, M. (2017). Estratégias de desenvolvimento: a pesquisa científica no campo do turismo de base comunitária. Gestión Turística, 27, p. 44-64.

Irving, M. de A. (2009). Reinventando a reflexão sobre o turismo de base comunitária. IN: Bartholo, R; Sansolo, D. G. \& Bursztyn, I. (Orgs). Turismo de Base Comunitária: diversidade de olhares e experiências brasileiras. Rio de Janeiro: Letra e Imagem, p. 108-121.

Irving, M. de. A. \& Azevedo, J. (2002). Turismo: o desafio da sustentabilidade. São Paulo: Futura.

Jamal, T. B. \& Getz, D. (1995). Collaboration theory and community tourism planning. Annals of Tourism Research, 22(1), p. 186-204. doi: https://doi.org/10.1016/01607383(94)00067-3

Joppe, M. (1996). Sustainable community tourism development revisited. Tourism Management, 17(7), p. 475-479. doi: https://doi.org/10.1016/S0261-5177(96)00065-9

Keogh, B. (1990). Public participation in community tourism planning. Annals of Tourism Research, 17, p. 449-465. doi: https://doi.org/10.1016/0160-7383(90)90009-G

Kibicho, W. (2008). Community-based tourism: A factor-cluster segmentation approach. Journal of Sustainable Tourism, 16(2), p. 211-231. doi: https://doi.org/10.2167/jost623.0

Koens, K., Postma, A. \& Papp, B. (2018) Is Overtourism Overused? Understanding the Impact of Tourism. In: A city context. Sustainability, 10(12), 4384. doi: https://doi.org/10.3390/su10124384

Laville, C. \& Dionne, J. (1999). A construção do saber: manual de metodologia da pesquisa em ciências humanas. Porto Alegre: Artmed; Belo Horizonte: Editora UFMG.

Madrigal, R. (1993). A tale of tourism in two cities. Annals of Tourism Research, 20, p. 336353. doi: https://doi.org/10.1016/0160-7383(93)90059-C

Mielke, E. J. C. \& Piegas, F. V. (2013). Turismo de Base Comunitária no Brasil. Insustentabilidade é uma Questão de Gestão. Turismo em Análise, 24(1), abr. doi: https://doi.org/10.11606/issn.1984-4867.v24i1p170-189

Mitchell, R. E. \& Reid, D. G. (2001). Community integration: Island tourism in Peru. Annals of Tourism Research, 28(1), p. 113-139. doi: http://dx.doi.org/10.1016/S01607383(00)00013-X 
Conti, B. R., Spinola, J. T., \& Saldanha, L. (2021, set./dez.). Turismo de base comunitária: uma revisão sistemática e bibliométrica da literatura

Okazaki, E. (2001). A community-based tourism model: Its conception and use. Journal of Sustainable Tourism, 16(5), 511-529. doi: https://doi.org/10.1080/09669580802159594

Panosso-Netto, A. \& Nechar, M. C. (2014). Epistemologia do Turismo: escolas teóricas e proposta crítica. Revista Brasileira de Pesquisa em Turismo, 8(1), 120-144. doi: https://doi.org/10.7784/rbtur.v8i1.719

Reed, M. G. (1997). Power relations and community-based tourism planning. Annals of Tourism Research, 24(3), p. 566-591. doi: https://doi.org/10.1016/S01607383(97)00023-6

Ruiz-Ballesteros, E. (2011). Social-ecological resilience and community-based tourism. An approach from Agua Blanca, Ecuador. Tourism Management, 32, p. 655-666. doi: https://doi.org/10.1016/j.tourman.2010.05.021

Sampaio, C. A. C. \& Coriolano, L. N. (2009). Dialogando com experiências vivenciadas em Marraquech e America Latina para compreensão do Turismo Comunitário e Solidário. Revista Brasileira de Pesquisa em Turismo, 3(1), p. 4-24. doi: https://doi.org/10.7784/rbtur.v3i1.125

Sampaio, C., Zechner, T., Henríquez, C., Coriolano, L. \& Fernandes, S. (2014). Turismo comunitário a partir de experiências brasileiras, chilenas e costarriquenha. Revista Brasileira de Pesquisa em Turismo, São Paulo, 8(1), p. 42-58, jan./mar. doi: http://dx.doi.org/10.7784/rbtur.v8i1.575

Sebele, L. S. (2010). Community-based tourism ventures, benefits and challenges: Khama Rhino Sanctuary Trust, Central District, Botswana. Tourism Management, 31, p. 136146. doi: https://doi.org/10.1016/j.tourman.2009.01.005

Shani A. \& Pizam A. (2012). Community Participation in Tourism Planning and Development. In: Uysal, M., Perdue, R. \& Sirgy, M. (edit.). Handbook of Tourism and Quality-of-Life Research. International Handbooks of Quality-of-Life. Springer, Dordrecht. p. 547-564. doi: https://doi.org/10.1007/978-94-007-2288-0_32

Sonego, M., \& Echeveste, M. S. (2016). Seleção de métodos para modularização no desenvolvimento de produtos: Revisão sistemática. Production, 26(2), p. 476-487. doi: https://doi.org/10.1590/0103-6513.138413

Souza, M. T. de; Silva, M. D. da \& Carvalho, R. de. (2010). Revisão integrativa: o que é e como fazer. Einstein, 8(1), p. 102-106. doi: http://dx.doi.org/10.1590/s167945082010rw1134

Vieira, R. S. \& Gomes, B. M. A. (2020). Produção científica internacional de turismo comunitário. Revista Americana de Empreendedorismo e Inovação, 2(3), p. 44-53.

Wearing, S. \& McDonald, M. (2002). The development of community-based tourism: Rethinking the relationship between tour operators and development agents as intermediaries in rural and isolated area communities. Journal of Sustainable Tourism, 10(3), p. 191-206. doi: https://doi.org/10.1080/09669580208667162 
Conti, B. R., Spinola, J. T., \& Saldanha, L. (2021, set./dez.). Turismo de base comunitária: uma revisão sistemática e bibliométrica da literatura

Western, D. (1995). Definindo ecoturismo. In: Lindberg, Kreg \& Hawkins, Donald E. (edit.) Ecoturismo - um guia para planejamento e gestão. Editora SENAC. São Paulo, p.1521.

Zapata M. J., Hall C. M., Lindo P. \& Vanderschaeghe M. (2011). Can community-based tourism contribute to development and poverty alleviation? Lessons from Nicaragua. Current Issues in Tourism. 00(0), p. 1-25. doi:

https://doi.org/10.1080/13683500.2011.559200 